\title{
O Colégio de Aplicação da UFRJ como unidade extensionista: a educação básica na universidade como espaço de formação e de produção de saberes entre professores
}

Isabel Van Der Ley Lima*

\begin{abstract}
Resumo:
A extensão universitária é um processo educativo, cultural e científico que articula o ensino e a pesquisa. Os Colégios de Aplicação, como unidades de educação básica universitárias, devem também ser espaços para o desenvolvimento de atividades extensionistas. Sendo assim, o objetivo deste trabalho é refletir sobre o papel do CAp-UFRJ como espaço produtor de ações de extensão. Para tanto, foram levantadas as ações registradas nos anos de 2012 a 2019. As ações desenvolvidas na escola têm dialogado de forma direta ou indireta com a formação de professores. Recentemente parte das ações passou a integrar o Complexo de Formação de Professores, política universitária que visa repensar a formação docente. Avalia-se, portanto, que a partir das ações desenvolvidas, o CAp cumpre seu papel como unidade de educação básica universitária imbuída da produção de conhecimento e da construção de práticas ligadas à formação docente.
\end{abstract}

\section{Palavras-chave:}

Extensão universitária. Formação de Professores. Saberes docentes. Práticas pedagógicas.

\begin{abstract}
:
University extension is an educational, cultural and scientific process that articulates teaching and research. The Application Schools (CAp), as university basic education units, should also be spaces for the development of extension activities. This work aims to reflect on the role of CAp-UFRJ as a space that produces extension actions. The actions registered between the years 2012 to 2019 were raised. They have dialogued directly or indirectly with teacher training. Recently, some actions became part of the Teacher Training Complex, a university policy that aims to rethink teacher training. We evaluate that from the actions developed, CAp fulfills its role as a basic university education unit where the production of knowledge and the construction of practices are related to teacher training.
\end{abstract}

\section{Keywords:}

University extension. Teacher Training. Teachers' knowledge. Pedagogical practices.

\footnotetext{
* Doutora em Educação, professora do setor de Ciências Biológicas do Colégio de Aplicação da Universidade Federal do Rio de Janeiro. E-mail: isabelvdl@gmail.com. ORCID iD: https://orcid.org/0000-0002-9379-6102.
} 


\section{Introdução}

Os Colégios de Aplicação (CAp), como unidades universitárias, têm em suas atribuições a realização de atividades de ensino pesquisa e extensão, aliadas à vocação para a formação de professores e a experimentação. O presente trabalho visa analisar o registro de ações de extensão no Colégio de Aplicação da Universidade Federal do Rio de Janeiro (CAp-UFRJ) e refletir sobre o papel do CAp como espaço produtor de ações de extensão em profunda relação com a formação docente nas diversas áreas do conhecimento.

Para tanto, será feita uma breve apresentação sobre a história e função extensão universitária e uma reflexão sobre a relação dos Colégios de Aplicação como unidades extensionistas; apresentando dados sobre as ações registradas no CAp-UFRJ entre os anos de 2012 e 2019.

Por fim, entendendo o papel dessas escolas na formação de professores, será discutida a relação entre essa formação e as ações de extensão a partir da experiência do Complexo de Formação de Professores, política universitária que visa repensar a formação docente na UFRJ.

\section{O papel da extensão como espaço de construção da universidade junto à sociedade}

A extensão universitária é eixo mais recente do tripé universitário, tendo como princípios a integração do ensino e da pesquisa com a construção de conhecimento de maneira dialógica com a sociedade.

A construção dessa integração com as demandas sociais varia entre os países e a história das universidades como instituição. A extensão surge no século XIX na Europa, como uma resposta às demandas da classe trabalhadora após a Revolução Industrial. Já nos Estados Unidos, é muito ligada ao setor empresarial, cumprindo um papel de desenvolver tecnologias que atendam a esse setor. $\mathrm{Na}$ América Latina, a extensão foi construída a partir da luta de movimentos sociais (PAULA, 2013).

No Brasil, a história da extensão universitária teve um caminho um pouco diferente do resto da América Latina, inclusive porque a criação das universidades ocorreu apenas nas décadas de 1920-1930. A extensão passou a ser prevista em lei a partir do Decreto n 19.851 de $1931^{1}$ (BRASIL, 1931) durante o ministério de Francisco Campos. O Decreto, em seu artigo no 109, indicava que a extensão universitária se destinava à "difusão de conhecimentos filosóficos, artísticos, literários e científico em benefício do aperfeiçoamento individual e coletivo" $\left(\$ 1^{\circ}\right)$. E que deveria ser feita por meio de cursos dentro e fora das universidades, conferências, propagandas ou demonstrações práticas.

$\mathrm{Na}$ análise de Rothen (2008), a Reforma Universitária de Francisco Campos se aproximava de um modelo norte-americano, ao apontar para a necessidade da universidade estabelecer laços de solidariedade com a sociedade, e entendendo que essa aproximação seria feita, então, através da extensão. Mas, segundo o autor, cabe lembrar que a indissociabilidade entre ensino, pesquisa e extensão não estavam presentes neste documento, nem como uma aspiração, o que muito provavelmente se deve ao fato de Campos compreender que a função pragmática da universidade era a formação de profissionais liberais.

Entretanto, a reflexão sobre um novo modelo de extensão, que tem como marco a construção do conhecimento em diálogo com a sociedade, foi fruto do trabalho dos movimentos sociais urbanos e rurais e teve como referência o trabalho de Paulo Freire (PAULA, 2013).

Em seu livro Extensão ou Comunicação?², Freire (2013) apresenta reflexões sobre o papel da extensão que seriam usadas como base para o debate acadêmico e político sobre o tema. A partir de estudos com agrônomos e agricultores chilenos, o autor faz uma crítica ao termo extensão, por sua relação significativa com a ideia de transmissão, entrega, doação messianismo, mecanicismo, invasão cultural, manipulação etc.

1. Decreto também conhecido como "Estatuto das Universidades Brasileiras" e que integrou o conjunto de reformas implantadas pelo então ministro da educação e da saúde pública, Francisco Campos, durante o governo de Getúlio Vargas.

2. Livro publicado em 1969, sob o título de Extensión o Comunicación?, pelo Instituto de Capacitación e Investigación en Reforma Agrária, em Santiago de Chile. 
A grande contribuição de Freire para o campo foi, portanto, a mudança de paradigma sobre a extensão, como um processo onde a universidade seria a detentora de um conhecimento científico que deveria ser levado à população que está fora dela (população essa que não deteria nenhum conhecimento relevante), para um paradigma de extensão dialógico, em que o conhecimento é produzido justamente no diálogo entre quem possui um conhecimento técnico e quem possui outras formas de conhecimento, de maneira que esses saberes não fossem hierarquizados (LIMA, 2018).

A contribuição Freire aliada a luta dos movimentos sociais, permitiu que a extensão voltasse ao debate político oficial no período de redemocratização na década de 1980. Em 1987, é criado Fórum de Pró-Reitores de Extensão da Universidades Públicas (FORPROEX) que passa a expressar um novo conceito de extensão baseado nos princípios da indissociabilidade e ação transformadora, com interação social e interdisciplinaridade. Logo depois, em 1988, é aprovado na Constituição o princípio da indissociabilidade ensino-pesquisa-extensão ${ }^{3}$ (FORPROEX, 2007). Neste contexto, a visão sobre o papel da extensão universitária supera uma visão tradicional de simples difusão e prestação de serviços para uma concepção de universidade em que a produção do conhecimento, via extensão, seria feita a partir da troca de saberes sistematizados, acadêmicos e populares.

\section{A extensão e os Colégios de Aplicação}

Os Colégios de Aplicação foram criados pelo Decreto nº 9.053 em março de 1946 (BRASIL, 1946) com a função de servir de campo de estágio para a Prática de Ensino dos cursos de licenciatura das Faculdades de Filosofia e como espaços de experimentação. O primeiro a ser fundado foi o Colégio de Aplicação da Universidade Federal do Rio de Janeiro em 1948 (CORREIA, 2017).

De acordo com Kinpara (1997), mesmo com as mudanças pedagógicas ao longo do tempo, essas escolas mantêm essas duas vertentes de serem espaço para a Prática de Ensino e a Experimentação. Ao analisar a história dos CAp, o autor analisa um relatório produzido a partir do um encontro realizado em 19944, quando essas escolas definiram linhas de ação acerca da extensão e da formação de professores.

Entre essas linhas, as escolas definem que, para uma educação de qualidade, ensino, pesquisa e extensão são indissociáveis e, portanto, os Colégios de Aplicação têm que estar inseridos nas políticas relacionadas a esses três eixos nas instituições e no país. Além disso, as ações de extensão deveriam ser desenvolvidas em parceria com as redes públicas de ensino e/ou unidades responsáveis pela formação de professores (KINPARA, 1997).

Assim, os CAp se reafirmam como unidade de educação básica inseridas dentro das universidades, entendendo que a qualidade de ensino depende da integração entre ensino, pesquisa e extensão. Reconhecendo e lutando também por uma maior participação nas reflexões sobre a formação de professores junto aos cursos de graduação.

\section{As ações de extensão no Colégio de Aplicação da UFRJ}

O CAp-UFRJ, assim como os demais colégios universitários, tem, como discutido na seção anterior, a atribuição de desenvolver atividades inseridas nos três eixos do tripé universitário. De acordo com seu regimento, entre as finalidades da escola está "promover a pesquisa e a extensão universitárias, com vistas à experimentação e reflexão sobre o processo educacional e o desenvolvimento de inovações pedagógicas e práticas inclusivas" (artigo $2^{\circ}$ ). A escola possui uma Direção Adjunta de Licenciatura, Pesquisa e Extensão

3. Artigo no 207 da Constituição Federal.

4. O autor relata que os CAp realizaram dois encontros em função do Plano Decenal de Educação Para Todos. O primeiro ocorreu em 1993 em Brasília, foi organizado pelo Ministério da Educação (MEC) e intitulado "Repensando as Escolas de Aplicação". O segundo foi em Florianópolis, em 1994, com o tema "O Plano Decenal e os Colégios de Aplicação". Esse segundo encontro analisou e ratificou as diretrizes estabelecidas no primeiro encontro e produziu um documento que ficou conhecido como "Relatório 1994" (KINPARA, 1997). 
(DALPE), que é o órgão planejador e articulador das ações ligadas à Licenciatura (Estágio Supervisionado de Graduação) e das atividades de pesquisa e extensão desenvolvidas (artigo 54º) (UFRJ, 2018a).

A partir do registro das ações de Extensão na DALPE 5 foi possível analisar os tipos de ações e quantidade de registros feitos entre os anos de 2012 e 2019 (Tabela 1). A partir dos dados, é possível perceber um aumento dos registros de ações de extensão a partir do ano de 2016 nas três modalidades de ações: projetos, cursos e eventos.

Tabela 1 - Quantidade de ações de extensão registradas por ano

\begin{tabular}{lcccc}
\hline Ano & Projetos & Cursos & Eventos & Total \\
\hline 2012 & 3 & 0 & 4 & 7 \\
2013 & 6 & 0 & 2 & 8 \\
2014 & 3 & 1 & 3 & 7 \\
2015 & 1 & 3 & 4 & 8 \\
2016 & 8 & 4 & 7 & 19 \\
2017 & 14 & 11 & 5 & 30 \\
2018 & 13 & 11 & 3 & 27 \\
2019 & 5 & 6 & 1 & 12 \\
\hline
\end{tabular}

Fonte: Elaborada pela autora.

É importante ressaltar que, em 2015, a UFRJ aprovou seu regulamento de extensão universitária (UFRJ, 2015). Com o novo regulamento, as ações passaram a ser aprovadas pelos colegiados das unidades e registradas pela Pró-Reitoria de Extensão que organizou o cadastramento a partir de editais de Registro Único de Ações de Extensão (RUA) ${ }^{6}$. Para serem registradas, as ações, entre outras exigências deveriam seguir as diretrizes definidas pelo FORPROEX (interação dialógica; interdisciplinaridade e interprofissionalidade; indissociabilidade ensino-pesquisa-extensão; impacto na formação do estudante; impacto na transformação social) e serem integradas a um dos oito programas articulados:

a. Construindo Cidades Humanas e Saudáveis: Articulação Campo-Cidade;

b. Cuidando da Vida: Metabolismo Natural e Metabolismo Social;

c. Expressões e Linguagens: Saberes em Movimento;

d. Transformação das Forças Produtivas Sociais;

e. Educação Pública, Formação Permanente e Educação Popular;

f. Internacionalismo, Identidades e Prazer;

g. Memória Cultural, Social e da Terra;

h. Complexo de Formação de Professores.

A maior parte das ações registradas no CAp estavam integradas aos programas Educação Pública, Formação Permanente e Educação Popular, Complexo de Formação de Professores e Expressões e Linguagens: Saberes em Movimento.

Também vale destacar que o aumento do registro ocorre após a mudança da carreira do Magistério Federal na Educação Básica, Técnica e Tecnológica (EBTT) ${ }^{7}$ a partir da Lei nº 12.772/2012. A lei anterior que regia a carreira, $\mathrm{n}^{\circ} 11.784 / 2008$, já previa em seu artigo $111^{\circ} \mathrm{o}$ ensino, a pesquisa e a extensão como atribuições da carreira EBTT, entretanto, a carreira foi modificada em 2012 pela Lei no 12.772 . A nova lei reafirma que o desenvolvimento e aperfeiçoamento do ensino, pesquisa e extensão como atribuição dos cargos do magistério federal (artigo $1^{\circ}, \S 6^{\circ}$ ) e determina que em seu artigo $14^{\circ}, \S 4^{\circ}$, que a progressão funcional da carreira EBTT devem ser feitas por desempenho, devendo "contemplar as atividades de ensino,

\footnotetext{
5. Dados organizados e cedidos pela DALPE durante a gestão 2017-2019 - "Desdobrando Tessituras".

6. Mais informações disponíveis em: https://xn--extenso-2wa.ufrj.br/index.php/registro/edital-rua/73-registro/rua-2019-2. Acesso em: 17 jun. 2020.

7. Cabe esclarecer que todos os docentes efetivos do CAp-UFRJ pertencem à carreira do Magistério Federal EBTT.
} 
pesquisa, extensão e gestão, cabendo aos conselhos competentes no âmbito de cada Instituição Federal de Ensino regulamentar os procedimentos do referido processo" (BRASIL, 2012). A partir daí, as instituições com docentes da carreira EBTT precisaram modificar suas tabelas de pontuação/avaliação, sendo necessário que o docente desenvolva ações dentro dos três eixos do tripé universitário para progredir nos níveis da carreira. O Conselho Universitário (CONSUNI) da UFRJ estabeleceu novas normas de avaliação em 2014 a partir da Resolução no 8 (UFRJ, 2014).

Desta forma, tanto a mudança do mecanismo de registro de ações na UFRJ, quanto a mudança na carreira do magistério EBTT, podem ter contribuído para o aumento de registro de ações a partir do ano de 2016. Vale destacar que em os dados de 2019 estão subestimados devido a migração dos registros de ações para um novo sistema ${ }^{8}$, no mesmo ano, de acordo com os dados da DALPE, 70\% do corpo docente fazia parte da equipe executora de alguma ação de extensão, seja ela registrada na própria unidade ou em outras unidades da Universidade. É válido dizer também que os técnicos administrativos em educação da carreira de nível superior podem coordenar ações de extensão, mas essa não é uma exigência da carreira. Durante a pesquisa, apenas um projeto era coordenado por uma técnica, mas como funcionária da biblioteca da escola, ela fica lotada no Sistema de Bibliotecas e Informação, que é um órgão suplementar do Fórum de Ciência e Cultura, logo, embora o projeto seja desenvolvido no CAp, ele não é registrado como uma ação da unidade.

\section{A extensão no CAp-UFRJ e a formação de professores}

Durante a análise dos dados tentou-se entender se havia algo de próprio na extensão realizada em uma unidade de educação básica inserida na universidade. Avaliando as ações desenvolvidas, foi possível perceber que elas dialogam de forma direta ou indireta com a formação de professores, pois mesmo em ações em que os docentes não são público-alvo, há o envolvimento de estudantes de graduação/licenciandos, promovendo o diálogo entre a formação inicial e continuada de professores.

A função de formar professores está presente nos CAp desde sua criação, sendo reafirmada ao longo de sua história como discutido na seção anterior. Recentemente parte das ações desenvolvidas no CAp-UFRJ passou a integrar o Complexo de Formação de Professores (CFP), política universitária que visa repensar a formação docente a partir dos pilares da "pluralidade" de experiências, "horizontalidade" dos saberes produzidos na Universidade e na Escola Básica e "integração" entre as diferentes instâncias formadoras de professores.

O CFP foi instituído em dezembro de 2018 considerando a relevância da formação de professores na função social da universidade; a necessidade de fortalecer as interações entre as unidades que trabalham com a formação de professores, conjugando as licenciaturas das áreas do conhecimento, Colégio de Aplicação e Faculdade de Educação; buscando articular as iniciativas existentes de ensino pesquisa e extensão sobre essa temática e institucionalizar a relação da UFRJ com as Secretarias de Educação e com instituições de ensino federais, estaduais e municipais parceiras (UFRJ, 2018b).

Gabriel (2019) narra que CFP começou a ser gestado três anos antes como um movimento institucional das Pró-Reitorias Acadêmicas, a Faculdade de Educação (FE) e o Colégio de Aplicação (CAp) e a Escola de Educação Infantil (EEI) ${ }^{9}$ com o objetivo de pensar coletivamente estratégias de articulação entre a UFRJ e as escolas da educação básica. Segundo autora, esse grupo foi movido por uma vontade política de que o papel de profissionalização do docente da educação básica assumisse uma dimensão institucional e extrapolasse as iniciativas isoladas das unidades e docentes.

O CFP se baseia na construção de um terceiro espaço ou casa comum para a formação de professores. Para Nóvoa (2019) esse terceiro espaço é onde são integrados os conhecimentos dos conteúdos científicos

8. Até 2018 a UFRJ utilizava o Sistema de Informação e Gestão de Projetos (SIGPROJ) e a partir de 2019, o registro das ações foi migrado para o Sistema Integrado de Gestão Acadêmica (SIGA) a fim de facilitar a integração entre os registros e a creditação das horas de extensão por parte dos estudantes de graduação.

9. A Escola de Educação Infantil foi integrada ao Colégio de Aplicação em 18 de junho de 2019, passando a se configurar como Setor de Educação Infantil. 
das disciplinas (Matemática, Biologia, História...) com os conhecimentos científicos do campo da Educação (fundamentos da didática, currículo, Psicologia...). Entretanto, o autor entende que, para a construção desse terceiro espaço ou casa comum, esses dois tipos de conhecimento seriam insuficientes para formar um professor, "se não construírem uma relação com o conhecimento profissional docente, com o conhecimento e cultura profissional dos professores" (NÓVOA, 2019, p. 9).

Para o autor, políticas de formação que levem a uma renovação das práticas docentes precisam compreender a importância da interação entre esses três espaços: profissional, universitário e escolar; pois é na interação entre eles que emergem as potencialidades transformadoras da profissão docente (Figura 1).

Figura 1 - Eixos da casa comum

Professor

Universidade

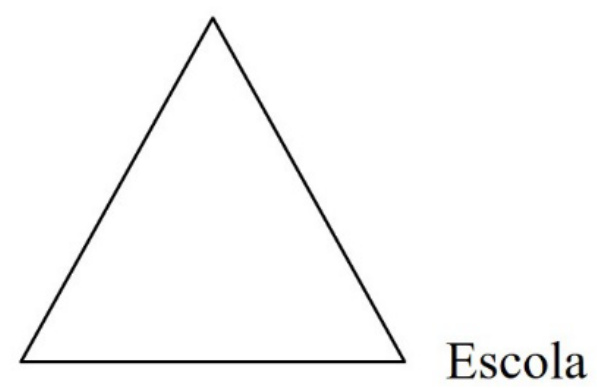

Fonte: Adaptada pela autora de Nóvoa (2019).

As atividades extensionistas desenvolvidas no CAp passaram a compor uma cartografia de ações do CFP que é apresentada às escolas das redes parceiras. Essas ações precisam seguir o princípio da "horizontalidade", que se traduz na reflexão de Nóvoa (2019) de que os diferentes saberes produzidos nos vértices da casa comum são igualmente importantes e devem ser legitimados. A universidade e a escola têm igual relevância na contribuição de saberes para a formação docente e essa não deve ser uma relação hierarquizada.

Essa visão não hierarquizada de saberes se aproxima muito da construção do conhecimento na extensão defendido por Freire (2013) e pelo FORPROEX. Assim, é possível pensar que a extensão pode ter um papel muito relevante na construção dessa casa comum para a formação de professores e que os CAp também têm muito a contribuir, já que seu corpo docente é composto por professores que atuam na educação básica e fazem pesquisa e extensão em diálogo com a formação docente. A relevância da extensão desenvolvida em parceria com as redes públicas de ensino e/ou unidades responsáveis pela formação de professores, como discutido, já é uma das linhas de ação defendida por essas escolas desde a década de 1990.

\section{Considerações finais}

A análise das ações de extensão registradas de 2012 a 2019 no CAp-UFRJ indicam que, nos últimos anos, o número de atividades extensionistas desenvolvidas sofreu influência de políticas externas (reformulação da carreira do Magistério Federal) e internas (reorganização das regras de extensão) à Universidade.

Todas as ações parecem dialogar de forma direta (docentes como público-alvo) ou indiretamente (estudantes de licenciatura como equipe executora) com a formação de professores e resultam em práticas que são aplicadas dentro e fora da própria escola.

O Complexo de Formação de Professores ressignifica o papel do CAp como unidade formadora de professores e expande o papel da escola como unidade extensionista, ampliando o diálogo com outras escolas públicas de educação básica. Esse movimento retoma uma reivindicação histórica dos CAp que considera que o ensino de qualidade precisa ser feito a partir da construção de práticas de ensino, pesquisa e extensão em diálogo com as demais escolas públicas e unidades formadoras de docentes na universidade. É importante destacar em especial a extensão como eixo potente para a construção do espaço da casa comum para uma nova perspectiva da formação de professores. 
Avalia-se, portanto, que a partir das ações desenvolvidas, o CAp cumpre seu papel como unidade de educação básica universitária imbuída da produção de conhecimento e práticas ligadas à formação docente. Também é possível perceber que as ações permitem a troca e construção coletiva entre docentes de diferentes escolas, possibilitando um trabalho horizontal e dialógico que impede a hierarquização de saberes e práticas, produzindo outras relações entre os professores da educação básica das diferentes redes públicas de ensino.

\section{Referências}

BRASIL. Ministério da Casa Civil. Lei no 11.784 , de 22 de setembro de 2008. Dispõe sobre a reestruturação do Plano Geral de Cargos do Poder Executivo - PGPE. Diário Oficial da União: seção 1, Brasília, DF, n. 184, p. 1, 23 set. 2008.

BRASIL. Ministério da Casa Civil. Lei no 12.772, de 28 de dezembro de 2012. Dispõe sobre a estruturação do Plano de Carreiras e Cargos de Magistério Federal. Diário Oficial da União: seção 1, Brasília, DF, ano 149, n. 251, p. 1, 31 dez. 2012.

BRASIL. Ministério da Educação. Decreto no 19851, de 11 de abril de 1931. Estabelece as bases do sistema universitário brasileiro. Diário Oficial da União: seção 1, Brasília, DF, p. 5800, 15 abr. 1931.

BRASIL. Decreto-Lei no 9.053, de 12 de março de 1946. Cria os ginásios de aplicação nas Faculdades de Filosofia do País. Diário Oficial da União: seção 1, Brasília, DF, p. 3693, 14 mar. 1946.

CORREIA, Evelline Soares. Colégios de Aplicação Pedagógica: sua história e seu papel no contexto educacional brasileiro. Revista Eletrônica Pesquiseduca, Santos, v. 9, n. 17, p. 116-129, 2017.

FÓRUM DE PRÓ-REITORES DE EXTENSÃO DAS UNIVERSIDADES PÚBLICAS BRASILEIRAS (FORPROEX). Extensão Universitária: organização e sistematização. Belo Horizonte: Coopmed, 2007.

FREIRE, Paulo. Extensão ou Comunicação? Rio de Janeiro: Paz e Terra, 2013.

GABRIEL, Carmen Teresa. Complexo de Formação de Professores: uma experiência (inter)institucional em curso. Profesorado: Revista de currículum y formación del profesorado, España, v. 23, n. 3, p. 189-209, jul./set. 2019.

KINPARA, Minoro Martins. Colégios de Aplicação e a prática de ensino: questões atuais. 1997. 175 f. Dissertação (Mestrado em Educação) - Faculdade de Educação, Universidade Estadual de Campinas, Campinas, 1997.

LIMA, Isabel Van Der Ley. O estágio em museus de ciência: o museu como espaço de produção do conhecimento e formação. Rio de Janeiro. 2018. Tese (Doutorado em Educação) - Departamento de Educação, Pontifícia Universidade Católica do Rio de Janeiro, Rio de Janeiro, 2018.

NÓVOA, Antônio. Os professores e a sua formação num tempo de metamorfose da escola. Educação \& Realidade, Porto Alegre, v. 44, n. 3, p. 1-9, 2019.

PAULA, João Antônio de. A extensão universitária: história, conceito e propostas. Interfaces: Revista de Extensão, Belo Horizonte, v. 1, n. 1, p. 5-23, jul./nov. 2013.

ROTHEN, João Carlos. A universidade brasileira na Reforma Francisco Campos de 1931. Revista Brasileira de História da Educação, Belo Horizonte, n. 17, p. 142-160, maio/ago. 2008.

UNIVERSIDADE FEDERAL DO RIO DE JANEIRO. Conselho Universitário. Resolução $n^{\circ}$ 8/2014, de 11 de setembro de 2014. Estabelece normas e critérios para o desenvolvimento na Carreira de Magistério Federal da UFRJ. Rio de Janeiro: Conselho Universitário, 2014.

UNIVERSIDADE FEDERAL DO RIO DE JANEIRO. Conselho Universitário. Resolução nº 7/2018, de 27 de setembro de 2018. Aprova o Regimento do Colégio de Aplicação da UFRJ. Rio de Janeiro: Conselho Universitário, 2018a.

UNIVERSIDADE FEDERAL DO RIO DE JANEIRO. Conselho Universitário. Resolução no 19/2018, de 27 de dezembro de 2018. Institui o Complexo de Formação de Professores na Estrutura Média da Universidade Federal do Rio de Janeiro. Rio de Janeiro: Conselho Universitário, 2018b.

UNIVERSIDADE FEDERAL DO RIO DE JANEIRO. Pró-Reitoria de Extensão. Resolução nº 1/2015, de 21 de maio de 2015. Aprova o Regulamento da Extensão Universitária na Universidade Federal do Rio de Janeiro (UFRJ). Boletim UFRJ: Atos da Pró-Reitoria de Extensão, Rio de Janeiro, n. 21, p. 12, 21 maio 2015.

Data de submissão: 19/06/2020

Data de aceite: $13 / 07 / 2020$ 